\title{
Content of Phenolic Compounds of Different Organ in Pimpinella brachycarpa Collected from Different Locations in Korea
}

\author{
${ }^{1}$ Nam Su Kim, ${ }^{1}$ Dae Hui Jung, ${ }^{1}$ Kwon Seok Jeon, ${ }^{1}$ Hong Woo Park and ${ }^{2}$ Sang Un Park \\ ${ }^{1}$ Forest Medicinal Resources Research Center, National Institute of Forest Science, Yeongju 36040, Korea \\ ${ }^{2}$ Department of Crop Science, Chungnam National University, 99 Daehak-ro, Yuseong-gu, Daejeon 34134, Korea
}

\section{Article history}

Received: 04-02-2020

Revised: 24-03-2020

Accepted: 23-05-2020

Corresponding Author:

Sang Un Park

Department of Crop Science, Chungnam National University, 99 Daehak-ro, Yuseong-gu, Daejeon 34134, Korea

Email:supark@cnu.ac.kr

Hong Woo Park

Forest Medicinal Resources

Research Center, National

Institute of Forest Science,

Yeongju 36040, Korea

Email: redrain39@korea.kr

\begin{abstract}
Pimpinella brachycarpa (Kom.) Nakai, reported to have antioxidant activity, is one of the most favored edible greens grown in Asian regions. The present study explores the variation in phenolic compounds in P. brachycarpa collected from different locations in Korea. Six phenolic compounds, i.e., catechin hydrate, chlorogenic acid, ferulic acid, benzoic acid, rutin and quercetin, were detected in the leaves, whereas among these compounds ferulic acid and quercetin were absent in the stems and benzoic acid and quercetin were absent in the roots of $P$. brachycarpa. The variation in phenolic compounds in plants from different locations was not as much as that among the different parts. The level of catechin hydrate content was much higher in the leaves than in the stems and roots. The amount of catechin hydrate in the leaves was 8.03 and 6.63 times higher than that of the highest catechin hydrate content in the roots and stems, respectively. The amount of benzoic acid accumulated was slightly higher (1.39 times) in the stems than the highest level in the leaves. The amount of ferulic acid accumulated was 1.9 times higher in the roots than the maximum level in the leaves. The amount of rutin accumulated was 1.91 times higher and 1.32 times lower in the roots than the highest levels in the stems and leaves, respectively. Our results indicate that phenolic compounds in $P$. brachycarpa varied significantly among the organs from different locations and the highest amount of phenolic compounds is contained in the leaves.
\end{abstract}

Keywords: Different Organ, Location, Phenolic Compounds, Pimpinella brachycarpa

\section{Introduction}

Pimpinella L. comprises about 150 species spread throughout the Old World (Pimenov and Leonov, 1993), making it one of the largest genera in the Apiaceae subfamily Apioideae. As the major constituent of the tribe Pimpinelleae (Downie et al., 2010), Pimpinella comprises mainly perennial herbs possessing cordateovoid or oblong-ovoid and slightly laterally compressed fruits constricted at their commissures, each with five filiform ribs ( $\mathrm{Pu}$ and Watson, 2005). It is an edible green, leafy vegetable commonly consumed in northeastern Asian regions (Sun et al., 2009) that belongs to Pimpinella L., family Umbelliferae (Na et al., 2007). In Korea, it is usually used as a seasoned vegetable dish consumed raw or parboiled to prepare namul. This species has been reported to have antioxidant activity in vitro (Lu et al., 2012; Kim et al., 2013a), ability to ameliorate hyperglycemia (Lee et al., 2013a) and antineuroinflammatory activity (Lee et al., 2013b). It displays 2,2-diphenyl-1-picrylhydrazyl (DPPH) radicalscavenging activity (Kim et al., 2013b) and has been shown to inhibit the production of intracellular ROS induced by hydrogen peroxide (Lu et al., 2012).

Food having phenolic compounds go to one of the main classes of secondary metabolites and are broadly disseminated in higher plants. Recently, research interest in these compounds has been encouraged by the latent health benefits arising from the antioxidant activity of these polyphenolic compounds, which protect the body's tissues against and the pathologies associated with oxidative stress, such as cancers, 
coronary heart disease and inflammation (Croft, 1998; Tapiero et al., 2002; Karakaya, 2004; Linseisen and Rohrmann, 2008).

Little information is available regarding the phenolic compounds found in different plant parts of $P$. brachycarpa with respect to plants from different locations within a country. Furthermore, to the best of our knowledge, no quantitative evaluation of phenolic compounds in P. brachycarpa has been reported thus far. Therefore, this study aimed to quantify phenolic compounds in different plant organs of $P$. brachycarpa collected from different locations in Korea using HPLC analyses.

\section{Materials and Methods}

\section{Plant Materials}

$P$. brachycarpa was identified by test guidelines in Fig. 1 was made by National Forest Seed and Variety Center (NFSV) in Korea Forest Service (KFS). Samples of $P$. brachycarpa were collected from six different locations, Mt. Hwaak, Mt. Duta, Mt. Irwol, Mt. Cheongok, Mt. Seokbyeong and Mt. Jeombong in Korea (Fig. 2). Geographic information of the collection locations is presented in Table 1. Collected samples were lyophilized at $-70^{\circ} \mathrm{C}$ for $72 \mathrm{~h}$. After lyophilization, samples were ground into a fine powder using a mortar and pestle.

\section{Phenolic Compounds Extraction}

Hundred milligrams of each sample was added to 2 $\mathrm{mL}$ of $80 \% \mathrm{MeOH}$ and then sonicated at $36^{\circ} \mathrm{C}$ for $1 \mathrm{~h}$ with vortexing every $20 \mathrm{~min}$ during the sonication. After centrifugation at $10000 \times g$ for $10 \mathrm{~min}$, the supernatants were transferred to a new tube and the remaining sludge was re-extracted twice using the same procedure. The supernatants were filtered through $0.45 \mu \mathrm{m}$ filters and transferred to a vial for analysis.

\section{HPLC Analysis of Phenolic Compounds}

HPLC analysis was performed using a Futecs model NS-4000 apparatus (Daejeon, Korea) with a C18 column ( $250 \mathrm{~mm} \times 4.6 \mathrm{~mm}, 5 \mu \mathrm{m}$; RStech, Daejeon, Korea). The mobile phase comprised a mixture of $0.15 \%$ aqueous acetic acid (solvent A) and $100 \% \mathrm{MeOH}$ (solvent B). The gradient program and conditions followed those described in previously published research (Cuong et al., 2018). The initial mobile phase composition was as follows: $5 \%$ solvent $\mathrm{B}$, followed by a linear gradient from 0 to $80 \%$ solvent B over 93 min and then a hold at $5 \%$ solvent $\mathrm{B}$ for an additional $5 \mathrm{~min}$. Phenolic compounds were detected at a wavelength of $280 \mathrm{~nm}$ and the column was maintained at $30^{\circ} \mathrm{C}$. The injection volume was $20 \mu \mathrm{L}$ and the flow rate was maintained at $1.0 \mathrm{~mL} / \mathrm{min}$. For peak identification and quantification, spike tests were performed and the content of phenolic compounds quantified using standard calibration curves. Calibration curves of standard were as follows, Catechin hydrate, $y=$ 7.889742787x - 40.24235366; Chlorogenic acid $y=$ 17.86310432x - 85.64433527; Ferulic acid $y=$ $39.27443921 \times+57.58486957$; benzoic acid $y=$ $7.525240872 \times-37.38700057$; rutin $y=8.09714215 x-$ 105.546569; quercetin, $y=14.00604622 \times$ 148.3452191). All standard in this work were purchased from Sigma-Aldrich (USA).

\section{Statistical Analysis}

The data were statistically analyzed using Statistical Analysis System software (SAS, system 9.4, 2013; SAS Institute, Inc., Cary, NC, USA). The statistical significance among means was evaluated using the Duncan's Multiple Range Test (DMRT) with a significance level of $p \leq 0.05$. All data are represented as the mean \pm standard deviation of triplicate tests.

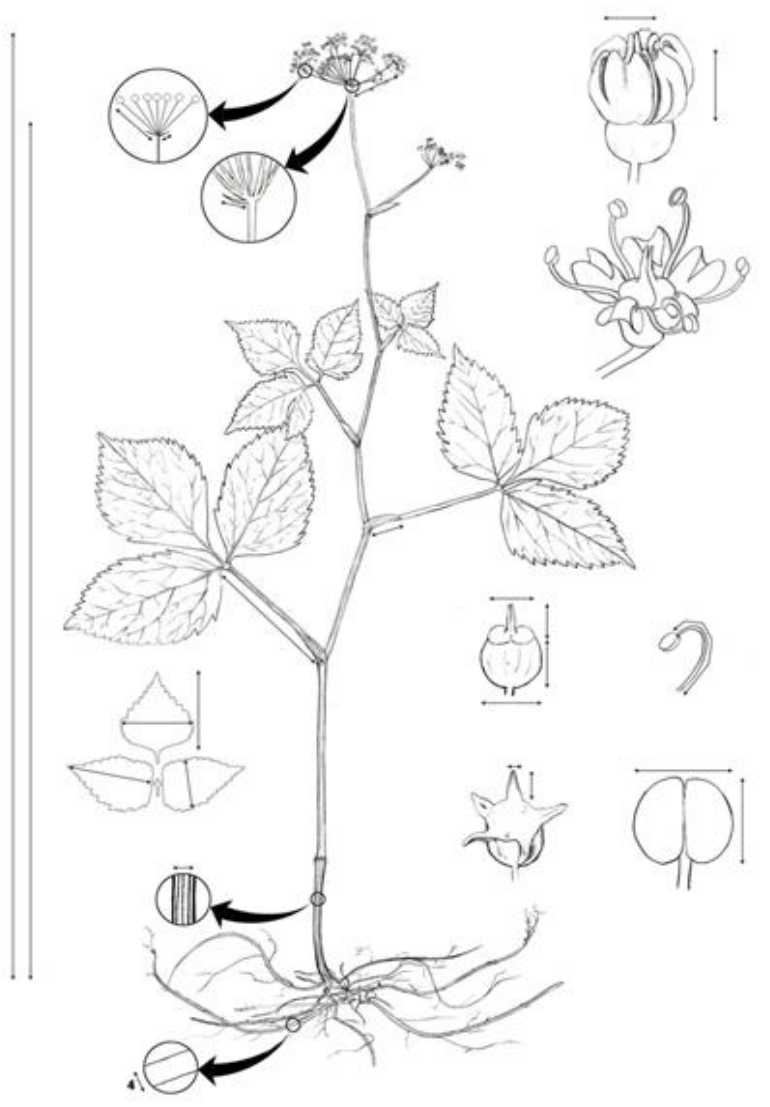

Fig. 1: The figure of test guidelines in P. brachycarpa pestle 


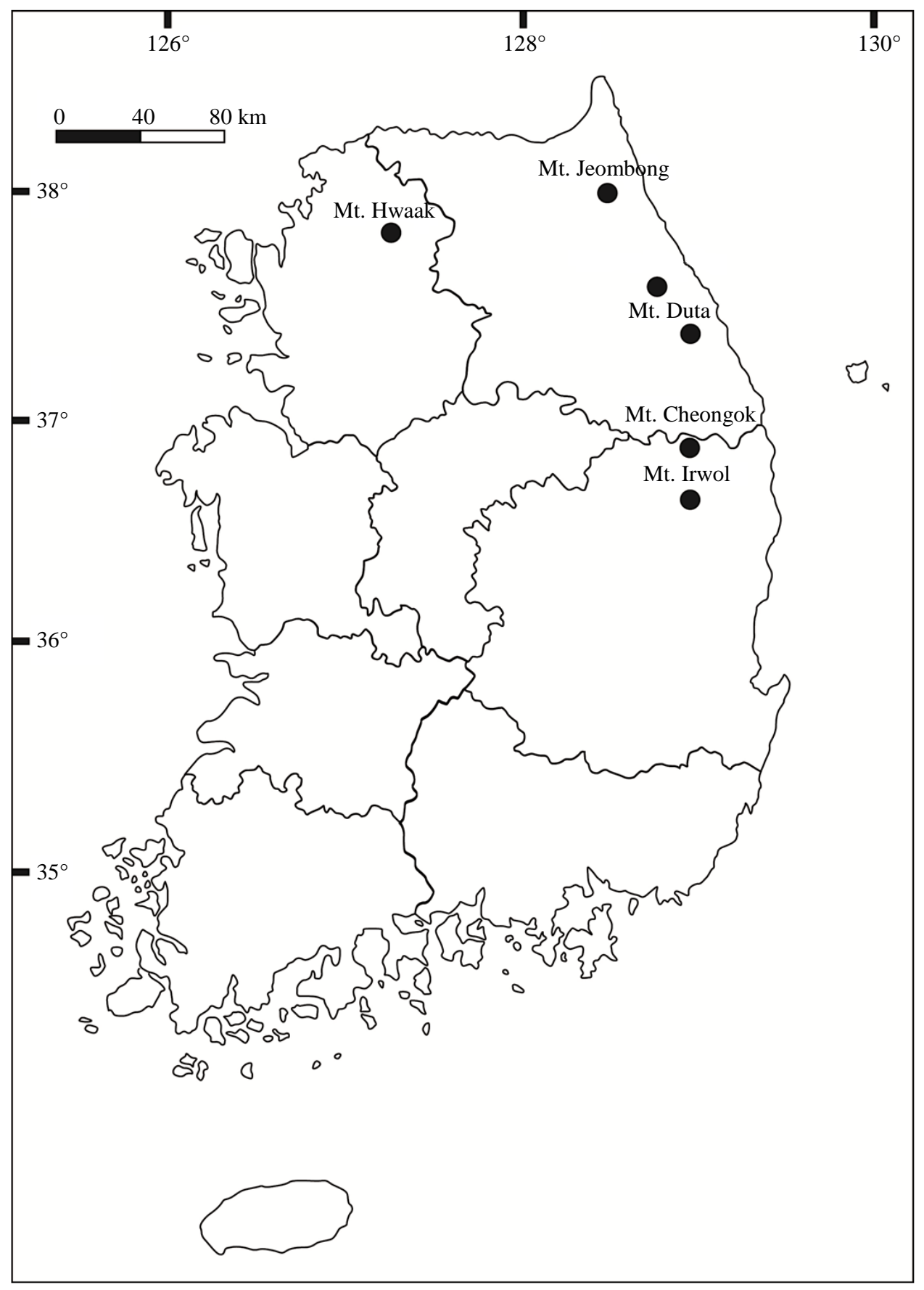

Fig. 2: The map of collected P. brachycarpa from different locations in Korea

Table 1: Geographical information of locations where Pimpinella brachycarpa was collected

\begin{tabular}{llll}
\hline Collection information & $\begin{array}{l}\text { Geographical information } \\
\text { Location }\end{array}$ & Eastern longitude & Altitude \\
\hline Mt. Hwaak & $37^{\circ} 59^{\prime} 25.05^{\prime \prime}$ & $127^{\circ} 33^{\prime} 09.21^{\prime \prime}$ & $823 \mathrm{~m}$ \\
Mt. Duta & $37^{\circ} 25^{\prime} 00.77^{\prime \prime}$ & $129^{\circ} 00^{\prime} 12.27^{\prime \prime}$ & $1216 \mathrm{~m}$ \\
Mt. Irwol & $36^{\circ} 48^{\prime} 14.42^{\prime \prime}$ & $129^{\circ} 06^{\prime} 07.67^{\prime \prime}$ & $1278 \mathrm{~m}$ \\
Mt. Cheongok & $37^{\circ} 02^{\prime} 21.61^{\prime \prime}$ & $128^{\circ} 57^{\prime} 54.62^{\prime \prime}$ & $1138 \mathrm{~m}$ \\
Mt. Seokbyeong & $37^{\circ} 35^{\prime} 16.83^{\prime \prime}$ & $128^{\circ} 53^{\prime} 37.91^{\prime \prime}$ & $969 \mathrm{~m}$ \\
Mt. Jeombong & $37^{\circ} 27^{\prime} 09.78^{\prime \prime}$ & $128^{\circ} 55^{\prime} 29.93^{\prime \prime}$ & $1105 \mathrm{~m}$ \\
\hline
\end{tabular}




\section{Results and Discussion}

\section{Phenolic Compounds in the Leaves of P. brachycarpa Collected from Different Locations in Korea}

Six different phenolic compounds, i.e., catechin hydrate, chlorogenic acid, ferulic acid, benzoic acid, rutin and quercetin were found in the leaves of $P$. brachycarpa collected from different locations in Korea. It was clearly observed that the content of phenolic compounds varied greatly with location (Table 2). The variation in content of phenolic compounds did not follow a similar trend for all the locations. Each location showed different levels of variability for each individual compound.

Among the phenolic compounds, the level of catechin hydrate content was much higher than that of any of the other compounds. The highest amount of catechin hydrate was $21.881 \mathrm{mg} / \mathrm{g}$ dry weight, whereas the highest amount of chlorogenic acid, ferulic acid, benzoic acid, rutin and quercetin was $1.685,0.020$, $0.053,0.323$ and 0.0252 , respectively. The content of catechin hydrate ranged from 21.881 to $11.340 \mathrm{mg} / \mathrm{g}$ dry weight among the six locations. The leaves of $P$. brachycarpa collected from Mt. Irwol showed the highest content (21.881) of catechin hydrate, followed by that from Mt. Hwaak (20.671). The amount of catechin hydrate was very similar in these two locations, whereas it varied considerably in the remaining four locations. However, within these four locations, there was not much variation. The content of catechin hydrate varied from 14.601 to 11.340 in these four locations. The variation in chlorogenic acid content in the leaves was also high among the locations. The range of chlorogenic acid content varied from 1.685 to $0.893 \mathrm{mg} / \mathrm{g}$ dry weight among the six locations. The leaf samples collected from Mt. Irwol showed the highest content of chlorogenic acid having 1.89 times higher chlorogenic acid content than that of the samples collected from Mt. Hwaak. The content of chlorogenic acid was $1.5,1.41$ and 1.33 times higher in the leaf samples of Mt. Irwol than that of samples from Mt. Duta, Mt. Seokbyeong and Mt. Cheongok, respectively.

Among the phenolic compounds, the accumulation of ferulic acid in the leaves was the lowest irrespective of location. The highest amount of ferulic acid was detected in the leaf samples of $P$. brachycarpa collected from the Mt. Seokbyeong region, whereas the lowest amount of this compound was found in the leaf samples from Mt. Cheongok. The variation was not largely different among the six sampled locations. The variation in benzoic acid content in the leaves also varied considerably between the highest and lowest content. For the rest of the compounds, the amount of accumulation was mostly similar among the locations. The range of benzoic acid content varied from 0.053 to $0.0264 \mathrm{mg} / \mathrm{g}$ dry weight among the six locations. The highest amount of benzoic acid was found in the leaves collected from Mt. Jeombong, whereas the lowest was detected in the leaf samples from Mt. Cheongok. The accumulation of rutin and quercetin content in the leaves of $P$. brachycarpa did not vary largely among the locations. The content of these two phenolic compounds was much closer to each other locations except a few. The rutin content ranged from 0.323 to $0.195 \mathrm{mg} / \mathrm{g}$ dry weight among the locations. The leaf samples collected from Mt. Duta showed the highest content of rutin, exhibiting 1.66 times higher rutin content than that of the sample collected from Mt. Hwaak. In contrast, quercetin content varied with a range of 0.0252 to $0.016 \mathrm{mg} / \mathrm{g}$ dry weight among the locations, where samples from Mt. Hwaak contained approximately 1.55 times higher levels than in samples from any other location.

Variation in Content of Phenolic Compounds in the Stems of P. brachycarpa Collected from Different Locations in Korea

Though six different phenolic compounds were detected in the leaves, in the stems, only four compounds, i.e., catechin hydrate, chlorogenic acid, benzoic acid and rutin, were identified in samples collected from the different locations in Korea (Table 3). Ferulic acid and quercetin were absent in the stems of $P$. brachycarpa. It was observed that the content of catechin hydrate was much lower in the stems, irrespective of location, compared to that in the leaves. The range of catechin hydrate content in the stems varied from 3.222 to $1.497 \mathrm{mg} / \mathrm{g}$ dry weight. The highest amount of catechin hydrate was detected in the stems of $P$. brachycarpa collected from Mt. Hwaak, accumulating 2.15 times higher catechin hydrate than that of the lowest content in the stem samples from Mt. Jeombong.

Table 2: Content of phenolic compounds in P. brachycarpa leaves from different mountain

\begin{tabular}{|c|c|c|c|c|c|c|c|}
\hline \multirow[b]{2}{*}{ Location } & \multicolumn{7}{|c|}{ Phenolic compound (mg/g dry weight) } \\
\hline & Catechin hydrate & Chlorogenic acid & Ferulic acid & Benzoic acid & Rutin & Quercetin & Total \\
\hline Mt. Hwaak & $20.67 \pm 0.29 b^{z}$ & $0.89 \pm 0.01 \mathrm{e}$ & $0.019 \pm 0.001 \mathrm{~b}$ & $0.0264 \pm 0.001 \mathrm{e}$ & $0.195 \pm 0.006 \mathrm{~d}$ & $0.0252 \pm 0.001 \mathrm{a}$ & $21.828 \pm 0.274 \mathrm{~b}$ \\
\hline Mt. Duta & $14.60 \pm 0.53 \mathrm{c}$ & $1.12 \pm 0.04 \mathrm{~d}$ & $0.017 \pm 0.001 \mathrm{~cd}$ & $0.0331 \pm 0.001 \mathrm{~d}$ & $0.323 \pm 0.014 \mathrm{a}$ & $0.017 \pm 0.001 \mathrm{c}$ & $16.112 \pm 0.546 \mathrm{c}$ \\
\hline Mt. Irwol & $21.88 \pm 0.70 \mathrm{a}$ & $1.69 \pm 0.07 \mathrm{a}$ & $0.017 \pm 0.001 \mathrm{bcd}$ & $0.0382 \pm 0.001 \mathrm{c}$ & $0.316 \pm 0.005 \mathrm{a}$ & $0.020 \pm 0.001 \mathrm{~b}$ & $23.958 \pm 0.778 \mathrm{a}$ \\
\hline Mt. Cheongok & $11.34 \pm 0.72 \mathrm{e}$ & $1.26 \pm 0.07 \mathrm{c}$ & $0.016 \pm 0.001 \mathrm{~d}$ & $0.034 \pm 0.001 \mathrm{~d}$ & $0.252 \pm 0.006 \mathrm{c}$ & $0.016 \pm 0.001 \mathrm{c}$ & $12.918 \pm 0.770 \mathrm{e}$ \\
\hline Mt. Seokbyeong & $12.32 \pm 0.35 \mathrm{~d}$ & $1.12 \pm 0.07 \mathrm{~cd}$ & $0.020 \pm 0.001 \mathrm{a}$ & $0.042 \pm 0.001 \mathrm{~b}$ & $0.283 \pm 0.004 \mathrm{~b}$ & $0.017 \pm 0.001 \mathrm{c}$ & $13.878 \pm 0.348 \mathrm{~d}$ \\
\hline Mt. Jeombong & $12.18 \pm 0.67 \mathrm{~d}$ & $1.55 \pm 0.06 \mathrm{~b}$ & $0.018 \pm 0.001 b c$ & $0.053 \pm 0.001 \mathrm{a}$ & $0.242 \pm 0.007 \mathrm{c}$ & $0.016 \pm 0.001 \mathrm{c}$ & $14.065 \pm 0.695 \mathrm{~d}$ \\
\hline
\end{tabular}

${ }^{\mathrm{z}}$ Values followed by different letters within a column indicate significant difference $(\mathrm{P}<0.05)$ between substrates for that parameter using Duncan's Multiple Range Test (DMRT) $(\mathrm{n} \geq 3$, mean $\pm \mathrm{SD})$ 
Table 3: Content of phenolic compounds in P. abrachycarpa stems from different mountain Phenolic compound (mg/g dry weight)

\begin{tabular}{llllll} 
Location & Catechin hydrate & Chlorogenic acid & Benzoic acid & Rutin & Total \\
\hline Mt. Hwaak & $3.222 \pm 0.193 \mathrm{a}^{\mathrm{z}}$ & $0.220 \pm 0.013 \mathrm{ab}$ & $0.038 \pm 0.002 \mathrm{~d}$ & $0.102 \pm 0.007 \mathrm{c}$ & $3.587 \pm 0.207 \mathrm{a}$ \\
Mt. Duta & $2.784 \pm 0.144 \mathrm{~b}$ & $0.217 \pm 0.008 \mathrm{~b}$ & $0.042 \pm 0.003 \mathrm{c}$ & $0.057 \pm 0.004 \mathrm{~d}$ & $3.107 \pm 0.154 \mathrm{~b}$ \\
Mt. Irwol & $3.299 \pm 0.149 \mathrm{a}$ & $0.235 \pm 0.014 \mathrm{a}$ & $0.046 \pm 0.001 \mathrm{c}$ & $0.047 \pm 0.004 \mathrm{e}$ & $3.633 \pm 0.150 \mathrm{a}$ \\
Mt. Cheongok & $1.640 \pm 0.268 \mathrm{~d}$ & $0.150 \pm 0.007$ & $0.061 \pm 0.002 \mathrm{~b}$ & $0.108 \pm 0.004 \mathrm{c}$ & $1.968 \pm 0.281 \mathrm{~d}$ \\
Mt. Seokbyeong & $2.393 \pm 0.170 \mathrm{c}$ & $0.149 \pm 0.002 \mathrm{c}$ & $0.071 \pm 0.001 \mathrm{a}$ & $0.128 \pm 0.002 \mathrm{a}$ & $2.746 \pm 0.171 \mathrm{c}$ \\
Mt. Jeombong & $1.497 \pm 0.182 \mathrm{~d}$ & $0.144 \pm 0.007 \mathrm{c}$ & $0.074 \pm 0.003 \mathrm{a}$ & $0.120 \pm 0.003 \mathrm{~b}$ & $1.851 \pm 0.191 \mathrm{~d}$ \\
\hline
\end{tabular}

${ }^{\mathrm{z}}$ Values followed by different letters within a column indicate significant difference $(\mathrm{P}<0.05)$ between substrates for that parameter using Duncan's Multiple Range Test (DMRT) ( $\geq 3$, mean \pm SD).

Table 4: Content of phenolic compounds in P. brachycarpa roots from different mountain

\begin{tabular}{|c|c|c|c|c|c|}
\hline \multirow[b]{2}{*}{ Location } & \multicolumn{5}{|c|}{ Phenolic compound (mg/g dry weight) } \\
\hline & Catechin hydrate & Chlorogenic acid & Benzoic acid & Rutin & Total \\
\hline Mt. Hwaak & $2.245 \pm 0.132 b^{z}$ & $0.013 \pm 0.000 \mathrm{c}$ & $0.028 \pm 0.002 b$ & $0.244 \pm 0.019 a$ & $2.529 \pm 0.131 b$ \\
\hline Mt. Duta & $2.726 \pm 0.077 \mathrm{a}$ & $0.022 \pm 0.001 \mathrm{a}$ & $0.036 \pm 0.001 \mathrm{a}$ & $0.167 \pm 0.011 b c$ & $2.952 \pm 0.085 \mathrm{a}$ \\
\hline Mt. Irwol & $1.679 \pm 0.088 \mathrm{c}$ & $0.012 \pm 0.000 \mathrm{c}$ & $0.031 \pm 0.003 b$ & $0.183 \pm 0.003 b$ & $1.904 \pm 0.077 \mathrm{c}$ \\
\hline Mt. Cheongok & $1.511 \pm 0.066 \mathrm{~cd}$ & $0.010 \pm 0.001 \mathrm{~d}$ & $0.031 \pm 0.003 b$ & $0.163 \pm 0.003 \mathrm{c}$ & $1.716 \pm 0.064 \mathrm{de}$ \\
\hline Mt. Seokbyeong & $1.458 \pm 0.072 \mathrm{~d}$ & $0.009 \pm 0.000 \mathrm{~d}$ & $0.030 \pm 0.001 b$ & $0.137 \pm 0.001 \mathrm{~d}$ & $1.635 \pm 0.072 \mathrm{e}$ \\
\hline Mt. Jeombong & $1.625 \pm 0.117 \mathrm{~cd}$ & $0.018 \pm 0.001 b$ & $0.038 \pm 0.002 \mathrm{a}$ & $0.143 \pm 0.002 \mathrm{~d}$ & $1.825 \pm 0.115 \mathrm{~cd}$ \\
\hline
\end{tabular}

${ }^{2}$ Values followed by different letters within a column indicate significant difference $(P<0.05)$ between substrates for that parameter using Duncan's Multiple Range Test (DMRT) ( $\mathrm{n} \geq 3$, mean \pm SD)

The highest amount of catechin hydrate in the stems was 6.79 times lower than the highest content in the leaves. The variation in chlorogenic acid content in the stems was not very large among the locations. The level of accumulation of chlorogenic acid content in the stems was also much lower than that in the leaves. The range of chlorogenic acid content varied from 0.235 to $0.144 \mathrm{mg} / \mathrm{g}$ dry weight among the six locations. The leaf samples collected from Mt. Irwol showed the highest content having 1.89 times higher chlorogenic acid content than that of the samples collected from Mt. Hwaak.

The amount of benzoic acid accumulated was slightly higher (1.39 times) in the stems than that in leaves considering the highest level of this compound. The range of benzoic acid content in the stems varied from 0.074 to $0.038 \mathrm{mg} / \mathrm{g}$ dry weight among the six locations. As in the leaves, the highest and the lowest amount of benzoic acid were also found in samples from Mt. Jeombong and Mt. Cheongok, respectively, in the stems. The range of rutin content in the stems varied from 0.128 to $0.047 \mathrm{mg} / \mathrm{g}$ dry weight among the six locations. The highest level of rutin was found in samples from Mt. Seokbyeong, accumulating 2.72 times higher amounts in the stems than that in the samples collected from Mt. Irwol.

Variation in Level of Phenolic Compounds in the Roots of P. brachycarpa Collected from Different Locations in Korea

In the roots, four phenolic compounds, i.e., catechin hydrate, chlorogenic acid, ferulic acid and rutin, were detected in $P$. brachycarpa samples collected from different locations in Korea (Table 4). Benzoic acid and quercetin were absent in the roots. The accumulation of catechin hydrate in the roots was much lower than the catechin hydrate content in the leaves. It is notable that the catechin hydrate content in the roots was even lower than that of the catechin hydrate content in the stems. The range of catechin hydrate content in the roots varied from 2.726 to $1.458 \mathrm{mg} / \mathrm{g}$ dry weight with 1.87 times higher accumulation in samples from Mt. Duta than that in samples from Mt. Seokbyeong. The chlorogenic acid content in the roots was the lowest among the different parts sampled. The level of chlorogenic acid accumulation in the roots was 76.60 and 10.68 times lower than that of chlorogenic acid accumulated in the leaves and stems, respectively, considering the highest values for all. The amount of ferulic acid accumulated was 1.9 times higher in the roots than that in leaves considering the highest level of this compound.

Lu et al. (2012) revealed that extract solution of $P$. brachycarpa had antioxidant effects at the cellular level. We revealed that $P$. brachycarpa accumulate some phenolic compounds, especially catechin hydrate was highly accumulated in leaves. Many previous reports revealed that catechin hydrate have effect on antioxidant (Mehra et al., 2013; Harper et al., 2010; Kaur et al., 2017; Kassim et al., 2011; Jing et al., 2018; Samanta et al., 2016). In addition to, other report revealed that catechin hydrate has effect on anti-inflammatory (Ashafaq et al., 2012), anti-cancer (Alshatwi, 2010) and improvement of cognitive impairment (Ahmed et al., 2013). Also, chlorogenic acid and rutin, which accumulated the most 
after catechin hydrate, was revealed about effect of antioxidant (Agunloye et al., 2019; Yun et al., 2012; Shafi et al., 2019), anti-inflammatory (Yoo et al., 2014; Gautam et al., 2016; Hwang et al., 2014) and anti-cancer (Hou et al., 2017; Saleh et al., 2019) by many reports.

The results of this study reveal that the variation in phenolic compounds was higher within the organs, i.e., leaf, stem and root, than that of the variation among locations. It is commonly assumed that the variation of any compound in a plant is among locations, mainly owing to the variation in edaphic factors like fertility status of the soil, soil texture, structure and $\mathrm{pH}$ and it might also be because of climatic factors such as temperature, rainfall and humidity. For the first time, this study quantitatively analyzed phenolic compounds in different plant organs of $P$. brachycarpa from different locations in Korea. Our results illustrate that the leaves of the studied species contained the highest number of phenolic compounds among the different organs. Content of phenolic compounds varied among different plant parts and even among locations. It is notable that the same location did not follow the same trend for phenolic compound content in different plant parts.

There have been some previous reports of variation in phenolic compounds such as the variation in glucosinolate content among the different parts and types of kohlrabi (Park et al., 2012) and the wide variations in the levels of phenolic compounds in different parts of tartary buckwheat (Uddin et al., 2013). Varietal differences in the antioxidative components in different plant parts including differences in the rutin content were also reported (Ohsawa and Tsutsumi, 1995), while varietal and environmental differences in vitamin $\mathrm{E}$ and phenolic acid (Oomah and Mazza, 1996a) have also been described. The phenolic compound composition may differ among parts within the individual plant as shown in several crops like turnip greens and turnip tops (Francisco et al., 2010), pak choi (Harbaum et al., 2007) and tronchuda cabbage (Ferreres et al., 2006; Harbaum et al., 2007). These results are consistent with the results our study where we found variation among the different parts within the individual plant. The levels of flavonoid and antioxidant in almonds depended more on cultivar than on differences of seasons (Bolling et al., 2010). In this study also, we found more variation owing to organs rather than location.

\section{Conclusion}

Compared with results of previous research studies, our findings are consistent that levels of different compounds differed with location and in organs of plants. The leaf was found to have the highest levels of total and individual phenolic compounds analyzed in the samples. Location also had a great influence on the content of phenolic compounds. From this study, we can easily conclude that location could play a vital role in the accumulation of different phenolic compounds and variation among the locations also showed significant influence. Organ- and location-specific phenolic compound profiles might be helpful for commercial use or production of phenolic compounds from $P$. brachycarpa.

\section{Acknowledgement}

This research was supported by the National Institute of Forest Science, Korea Forest Service, Republic of Korea (Project No. FG0502-2017-01)

\section{Author's Contributions}

Nam Su Kim, Dae Hui Jung, Kwon Seok Jeon and Hong Woo Park: Performed the experiments, analyzed the data and prepare the manuscript.

Sang Un Park: Designed the experiments, coordinated the implementation of research work.

\section{Ethics}

This manuscript has not been published or presented elsewhere in part or in entirely and is not under consideration by another journal. All the authors have approved the manuscript and agree with submission to your esteemed journal. There are no conflicts of interest to declare.

\section{References}

Agunloye, O.M., G. Oboh, A.O. Ademiluyi, A.O. Ademosun and A.A. Akindahunsi et al., 2019. Cardio-protective and antioxidant properties of caffeic acid and chlorogenic acid: Mechanistic role of angiotensin converting enzyme, cholinesterase and arginase activities in cyclosporine induced hypertensive rats. Biomed. Pharmacoth., 109: 450-458.

Ahmed, M.E., M.M. Khan, H. Javed, K. Vaibhav and A. Khan et al., 2013. Amelioration of cognitive impairment and neurodegeneration by catechin hydrate in rat model of streptozotocin-induced experimental dementia of Alzheimer's type. Neurochem. Int., 62: 492-501.

Alshatwi, A.A., 2010. Catechin hydrate suppresses MCF-7 proliferation through TP53/Caspasemediated apoptosis. J. Exp. Clin. Cancer Res., 29: 167-167.

Ashafaq, M., S.S. Raza, M.M. Khan, A. Ahmad and H. Javed et al., 2012. Catechin hydrate ameliorates redox imbalance and limits inflammatory response in focal cerebral ischemia. Neurochem. Res., 37: 1747-1760. 
Croft, K.D., 1998. The chemistry and biological effects of flavonoids and phenolic acids. Annals New York Acad. Sci., 854: 435-442.

Cuong, D., S.J. Kwon, J. Jeon, Y.J. Park and J.S. Park et al., 2018. Identification and characterization of phenylpropanoid biosynthetic genes and their accumulation in bitter melon (Momordica charantia). Molecules, 23: 469-469.

Downie, S.R., K. Spalik, D.S. Katz-Downie and J.P. Reduron, 2010. Major clades within Apiaceae subfamily Apioideae as inferred by phylogenetic analysis of nrDNA ITS sequences. Plant Div. Evolut., 128: 111-136.

Ferreres, F., C. Sousa, V. Vrchovská, P. Valentão and J.A. Pereira et al., 2006. Chemical composition and antioxidant activity of tronchuda cabbage internal leaves. Eur. Food Res. Technol., 222: 88-98.

Francisco, M., P. Velasco, D.A. Moreno, C. GarcíaViguera and M.E. Cartea, 2010. Cooking methods of Brassica rapa affect the preservation of glucosinolates, phenolics and vitamin C. Food Rese. Int., 43: 1455-1463.

Gautam, R., M. Singh, S. Gautam, J.K. Rawat and S.A. Saraf et al., 2016. Rutin attenuates intestinal toxicity induced by Methotrexate linked with anti-oxidative and anti-inflammatory effects. BMC Complementary Alterna. Med., 16: 99-99.

Harbaum, B., E.M. Hubbermann, C. Wolff, R. Herges and Z. Zhu et al., 2007. Identification of flavonoids and hydroxycinnamic acids in Pak Choi varieties (Brassica campestris L. ssp. chinensis var. communis) by HPLC-ESI-MS $\mathrm{n}$ and NMR and Their Quantification by HPLC-DAD. J. Agric. Food Chem., 55: 8251-8260.

Harper, J.K., J.A. Doebbler, E. Jacques, D.M. Grant and R.B. Von Dreele, 2010. A combined solid-state NMR and synchrotron X-ray diffraction powder study on the structure of the antioxidant (+)-catechin 4.5-hydrate. J. Am. Chem. Society, 132: 2928-2937.

Hou, N., N. Liu, J. Han, Y. Yan and J. Li, 2017. Chlorogenic acid induces reactive oxygen species generation and inhibits the viability of human colon cancer cells. Anti-Cancer Drugs, 28: 59-65.

Hwang, S.J., Y.W. Kim, Y. Park, H.J. Lee and K.W. Kim, 2014. Anti-inflammatory effects of chlorogenic acid in lipopolysaccharide-stimulated RAW 264.7 cells. Inflamm. Res., 63: 81-90.

Jing, X., J. Zhang, Z. Huang, Y. Sheng and L. Ji, 2018. The involvement of $\mathrm{Nrf} 2$ antioxidant signalling pathway in the protection of monocrotaline-induced hepatic sinusoidal obstruction syndrome in rats by (+)-catechin hydrate. Free Radical Res., 52: 402-414.
Karakaya, S., 2004. Bioavailability of phenolic compounds. Critical Rev. Food Sci. Nutrition, 44: 453-464.

Kassim, M.J., M.H. Hussin, A. Achmad, N.H. Dahon and T.K. Suan et al., 2011. Determination of total phenol, condensed tannin and flavonoid contents and antioxidant activity of Uncaria gambir extracts. Indonesian J. Pharmacy.

Kaur, R., R. Rajput, P. Nag, S. Kumar and M. Singh, 2017. Synthesis, characterization and evaluation of antioxidant properties of catechin hydrate nanoparticles. J. Drug Delivery Sci. Technol., 39: 398-407.

Kim, S.J., S.C. Min, H.J. Shin, Y.J. Lee and A.R. Cho et al., 2013a. Evaluation of the antioxidant activities and nutritional properties of ten edible plant extracts and their application to fresh ground beef. Meat Sci., 93: 715-722.

Kim, S.J., W.T. Park, M.R. Uddin, Y.B. Kim and S.Y. Nam et al., 2013b. Glucosinolate biosynthesis in hairy root cultures of broccoli (Brassica oleracea var. italica). Natural Product Commun., 8: 217-220.

Lee, S.J., H.N. Choi, M.J. Kang, E. Choe and J.H. Auh et al., 2013a. Chamnamul [Pimpinella brachycarpa (Kom.) Nakai] ameliorates hyperglycemia and improves antioxidant status in mice fed a high-fat, high-sucrose diet. Nutrit. Res. Practice, 7: 446-452.

Lee, S.Y., E. Moon, S.Y. Kim and K.R. Lee, 2013 b. Quinic acid derivatives from Pimpinella brachycarpa exert anti-neuroinflammatory activity in lipopolysaccharide-induced microglia. Bioorganic Med. Chem. Let., 23: 2140-2144.

Linseisen, J. and S. Rohrmann, 2008. Biomarkers of dietary intake of flavonoids and phenolic acids for studying diet-cancer relationship in humans. Eur. J. Nutrit., 47: 60-60.

Lu, J., W. Qian, L. Xu, G. Huang and W. Cong et al., 2012. Phytochemical composition and toxicity of an antioxidant extract from Pimpinella brachycarpa (Kom.) Nakai. Environ. Toxicol. Pharmacol., 34: 409-415.

Mehra, P., A. Koul and D.D. Bansal, 2013. Studies on Antioxidant Role of (+)-Catechin hydrate in high sucrose high fat diet induced oxidative stress. Am. J. Biomed. Sci., 5: 161-170.

Na, H., K.W. Kim, Y. Kwack, S.K. Kim and C. Chun, 2007. Comparative anatomy of embryogenic and non-embryogenic calli from pimpinella brachycarpa. J. Plant Biol., 50: 344-350.

Ohsawa, R. and T. Tsutsumi, 1995. Inter-varietal variations of rutin content in common buckwheat flour (Fagopyrum esculentum Moench.). Euphytica, 86: 183-189. DOI: 10.1007/BF00016355 
Oomah, B.D. and G. Mazza, 1996. Flavonoids and antioxidative activities in buckwheat. J. Agric. Food Chem., 44: 1746-1750. DOI: 10.1021/jf9508357

Park, W.T., J.K. Kim, S.U. Park, S.W. Lee and X. Li et al., 2012. Metabolic profiling of glucosinolates, anthocyanins, carotenoids and other secondary metabolites in Kohlrabi (Brassica oleracea var. gongylodes). J. Agric. Food Sci., 60: 8111-8116.

Pimenov, M.G. and M.V.E. Leonov, 1993. The genera of the Umbelliferae: A nomenclator. Royal Botanic Gardens, Kew.

$\mathrm{Pu}$, F.T. and M.F. Watson, 2005. Flora of China Pimpinella L. (Wu ZY, Raven PH. eds.). Sci. Press Missouri Botanical Garden Press, 14: 93-104.

Saleh, A., H.M. ElFayoumi, M. Youns and W. Barakat, 2019. Rutin and orlistat produce antitumor effects via antioxidant and apoptotic actions. NaunynSchmiedeberg's Archives Pharmacol., 392: 165-175.

Samanta, A., S. Chanda, B. Bandyopadhyay and N. Das, 2016. Establishment of drug delivery system nanocapsulated with an antioxidant (+)-catechin hydrate and sodium meta borate chelator against sodium fluoride induced oxidative stress in rats. J. Trace Elements Med. Biol., 33: 54-67.
Shafi, W., S. Mansoor, S. Jan, D.B. Singh and M. Kazi et al., 2019. Variability in catechin and rutin contents and their antioxidant potential in diverse apple genotypes. Molecules, 24: 943-943.

Sun, G., S. Diao and D. Yao, 2009. GC-MS analysis of essential oil from Spuriopimpinella brachycarpa. J. Northeast Forestry Univ., 37: 102-103.

Tapiero, H., K.D. Tew, G.N. Ba and G. Mathe, 2002. Polyphenols: do they play a role in the prevention of human pathologies? Biomed. Pharmacoth., 56: 200-207.

Uddin, M.R., X. Li, Y.B. Kim, S.C. Chae and S.J. Kim et al., 2013. Phenolic compounds in different organs of tartary buckwheat (Fagopyrum tataricum Gaertn.) cultivars. Australian J. Crop Sci., 7: 1861-18.

Yoo, H., S.K. Ku, Y.D. Baek and J.S. Bae, 2014. Antiinflammatory effects of rutin on HMGB1-induced inflammatory responses in vitro and in vivo. Inflamm. Res., 63: 197-206.

Yun, N., J.W. Kang and S.M. Lee, 2012. Protective effects of chlorogenic acid against ischemia/reperfusion injury in rat liver: Molecular evidence of its antioxidant and anti-inflammatory properties. J. Nutrit. Biochem., 23: 1249-1255. 